\title{
Development of double axial transverse rotary mechanism for crop residue cutting, shredding and weeding
}

\author{
C. Yella Swami, A.K. Dave and Ravikant V. Adake
}

Received : 23.07.2018; Revised : 20.08.2018; Accepted : 05.09.2018

See end of the Paper for authors' affiliation Correspondence to :

C. Yella Swami Department of Farm Machinery and Power Engineering, Indira Gandhi Krishi Vishwavidyalaya, Raipur (C.G.) India Email : yellaswami@gmail.com
- ABSTRACT : Methods of weeding and crop residue mulch with minimum soil disturbance have greater importance in conservation agriculture. Considering the importance of weeding and crop residue mulch in conservation agriculture point of view the project was envisaged to develop double axial transverse rotary mechanism anticipating that there would be a minimum soil disturbance without compromising cutting efficiency, shredding efficiency and weeding efficiency. The prototype developed and tested at Farm Machinery Research Workshop, Central Research Institute for Dry land Agriculture (CRIDA), Hyderabad during 2016-17. Experiments were conducted with sorghum stalk to finalized critical parts such as blade, rotor length, rotor speed, forward speed for development of prototype. Prototype has two cylindrical rotors having triangular edged tooth plates on its periphery rotating in opposite directions in plane. The rotational speed of cylinders was $450 \mathrm{rpm}$ and suitable for $3 \mathrm{~km} / \mathrm{h}$ travel speed of tractor. The machine was tested in field conditions for sorghum, maize, castor and red gram crop stem cutting and shredding and weeding. The cutting efficiency of finalized model for sorghum, maize, castor, red gram was found to be 94 per cent, 81 per cent, 72 per cent and 68 per cent, respectively. The shredding of finalized model for sorghum, maize, castor, red gram was found to be 69 per cent, 61 per cent, 46 per cent and 41 per cent, respectively. The performance of prototype in terms of cutting and shredding efficiency was found to be superior for 25 per cent stem moisture compared to 45 per cent and 65 per cent stem moisture and it was true in all the crop studied. The weeding efficiency of newly developed model was comparatively lower it disturbed only one inch soil depth as against 1.5-2.0 inch soil depth which indicated that the soil disturbance for per unit area was about 33-50 per cent less when weeding was done with newly developed rotary tiller. Overall, the prototype was found to suit the theme of conservation agriculture.

- KEY WORDS : Cutting efficiency, Shredding efficiency, Weeding efficiency, Stem moisture, Crop residue, Rotor speed

- HOW TO CITE THIS PAPER : Swami, C. Yella, Dave, A.K. and Adake, Ravikant V. (2018). Development of double axial transverse rotary mechanism for crop residue cutting, shredding and weeding. Internat. J. Agric. Engg., 11(2) : 339-345, DOI: 10.15740/HAS/IJAE/11.2/339-345. Copyright@2018: Hind Agri-Horticultural Society. 